\title{
Intelligently Discussing Design: Jones and Reiss's Teaching about Scientific Origins: Taking Account of Creationism
}

\author{
Teaching about Scientific Origins: Taking Account of Creationism, by Leslie S. Jones \\ and Michael J. Reiss (editors). Vol. 277 of Studies in the Postmodern Theory of Education, \\ Joe L. Kincheloe and Shirley R. Steinberg (general editors). New York: Peter Lang, \\ 2007. Pp. $x+213$. S/b $\$ 29.95$
}

\section{Michael Jordan}

Published online: 27 August 2008

(C) Springer Science + Business Media, LLC 2008

Consider the curious case of the theory of evolution. In the almost 150 years since the publication of Darwin's The Origin of Species, every major scientific discovery in biology, genetics, paleontology, etc. has reinforced Darwin's original insight, remedied some of the gaps and errors (e.g. modified Lamarkism) in Darwin's account, and, in general, elevated evolution from just one theory about the development of life to the theory about the development of life. Despite the differences and squabbles that remain among evolutionists, evolution has come to occupy the central position in contemporary biology. There hasn't been a single, notable scientific discovery in the last 150 years to challenge the general evolutionary approach.

And yet, despite all this, the teaching of evolution is controversial in some quarters. Surveys show that close to $50 \%$ of Americans do not accept the truth of evolution. One of the most striking images from the recent political primary campaigns was the image of several Republican presidential candidates refusing to raise their hands when asked which of them accepted evolution.

This is not, historically, an unprecedented situation. One clear parallel can be seen in the Catholic Church's resistance to Copernican and Galilean cosmology. But there are still differences between the two cases. There is no longer a monolithic church to dictate belief, we generally see ourselves as more scientifically sophisticated and advanced. And yet, despite the repeated legal defeats handed to Intelligent Design Creationists and others who

\section{Jordan $(\bowtie)$}

Iona College,

715 North Avenue,

New Rochelle, NY 10801, USA

e-mail: mjordan@iona.edu oppose evolution, there are still those $50 \%$ who doubt and those Republican candidates who refused to raise their hands. Under these circumstances what can evolutionists say to their anti-evolution brethren?

In Teaching about Scientific Origins: Taking Account of Creationism, Leslie S. Jones, a science educator in the biology department at Valdosta State University, and Michael J. Reiss, a professor of science education at the Institute of Education, University of London, and also a Priest in the Church of England, present 13 essays by a variety of writers that attempt to answer that question.

Almost all the essays in this collection are written by committed evolutionists, all of whom are involved in educational endeavors. This leads to a situation where the overwhelming emphasis is on the question of how science (and science teachers) should respond to religious challenges. Thus, the burden of proof seems to fall squarely on the scientists. This in itself is problematic. After all, it's not simply a case of (some) science disagreeing with (some) religion; it is also a case of (some) religion disagreeing with (some) science. But religious critics are not really being called on here to supply a defense of their part of the controversy. This may just be a function of the anthology itself, but it does, I think, present an unfair advantage to the anti-evolution religious mindset. Just as in a court of law the burden of proof falls on the prosecution, so here the burden of proof falls on science to make its case.

The historical background to the evolution/creationism controversy is summarized nicely in the useful essay by Randy Moore, "The History of the Evolution/Creationism Controversy and Likely Future Developments." Moore supplies a catalog of the major legal battles waged and lost by the creationists and sketches the strategies that have 
been developed by the creationists to somehow avoid the ramifications of these legal defeats. This essay serves as an excellent background to the issues taken up by the other authors in the book.

Of the thirteen essays in this collection, only three take the fairly uncompromising stand that Intelligent Design Creationism (or any other sort of creationism, for that matter) has absolutely no place in a science classroom. This position is stated most clearly in Robert Pennock's "How Not to Teach the Controversy about Creationism." Pennock, the author of Tower of Babel: The Evidence against the New Creationism and what can be seen as a companion anthology to that book, Intelligent design creationism and its critics: philosophical, theological, and scientific perspectives, has made a career of resisting the inclusion of creationism in science courses, and his essay here further reflects and develops that previous concern. In the course of his essay Pennock examines the different strategies used by Intelligent Design Creationism advocates (hereafter, IDCs) to get around a series of recent legal defeats. In many cases, the strategies rest on misstatement and misrepresentation. In response to the suggestion that Intelligent Design be taught as an alternative to evolutionary theory, Pennock says:

Evolutionary theory has been developing for over a hundred and fifty years since Darwin published the Origin, and it is absurd to suggest that one should continue to lay out the options neutrally as though it were still an open question. This would be equivalent to presenting the evidence for heliocentrism neutrally. Indeed, it would be pedagogically irresponsible to misrepresent the findings of science by teaching them in this way. (p. 71)

Pennock then summarizes his position as follows:

What should be educators' and citizens' response when IDC's lobby in Kansas and elsewhere to 'teach the controversy'? We should respond with a slogan of our own: Teach only real science in science classes, not creationist pseudoscience. (p. 72)

David F. Jackson, in his essay, "The Personal and the Professional in the Teaching of Evolution," echoes this position when he says:

My professional position on 'the evolution/creationism controversy' is very simply what might be described as the 'party line' among science educators: Darwinism, Deep Time, and the Big Bang should be taught, and various forms of creationism (all of whose origins, if we are to be honest, are of a religious nature) should not be taught, in US public school science classrooms. (p. 161)
Jackson, who in this essay is especially concerned with the training of prospective middle school science teachers, does, however, believe that, as a practical matter, science teachers cannot simply ignore religious attitudes and beliefs but must find a way to approach these beliefs with a certain degree of respect and sensitivity. He says:

In framing the general argument in the context of teaching and teacher education, I emphasize the serious consideration of 'middle ground' positions espoused by some respected scientists...not because I personally find their arguments convincing (which I do not), but because I believe that they are, in practice, the only hope of serving as a 'wedge' to initiate at least a minimal opening of a substantive and potentially productive interaction between people with polarized views. (pp. 169-170)

David Mercer, in "Capturing the Educational Potential of "Creation Science Debates," is also concerned with avoiding polarization. As Mercer sees it, the creation/ evolution debate all too often becomes

...excessively preoccupied with attempting to resolve larger debates in epistemology involved with demarcating science and identifying and describing the philosophical essences of science and religion. (p. 43)

For Mercer these "larger debates in epistemology" belong in the scholarly journals, not the popular debates. As an alternative to this scholarly discussion Mercer suggests:

Rather than being drawn into answering fundamental issues of epistemology in the science classroom, creation science and intelligent design could be more constructively framed as 'local knowledge' containing some elements loosely associated with contemporary biology. Within this more pragmatic framework, it would be relatively easy to assess the aims, cognitive style, modes of justification, and general (lack of) instrumental value of such claims. It would be unlikely that such claims would warrant much time in the science curriculum. (p. 55)

But to what effect? In light of the apparent uselessness of such explanations in the science classroom, why introduce them at all?

Engagement in endless battles over folk epistemologies of science, such as those documented here, should not be allowed to direct energy in popular scientific discourse and science education away from engagement in the more important immediate project of encouraging a better appreciation of the actual practices of the sciences and their immediate social implications. (pp. 55-56) 
This theme of avoiding polarization, of introducing IDC as a way of providing a wedge to evolution studies, is taken up and endorsed to one extent or another by most of the essays in this collection. These calls amount not so much to calls for resolutions of the controversy, as to ways of managing the controversy. A number of writers strive to find ways to expose students to evolutionary theory without excessively challenging the religious beliefs that make these students reluctant to even hear about evolution. And so Leslie Jones, in "Teaching for Understanding Rather than Expectation of Belief," recounts her experiences in teaching evolution to fundamentalist students. Jones observes:

Regardless of who is responsible for the controversy, and I do think that scientific arrogance is partially to blame, the scientific community can no longer afford to ignore the fact that biological education is being crippled by religious aversion to evolution. (p. 195)

And in the introductory essay written by Jones and Reiss, "Cultural Authority and the Polarized Nature of the Evolution/Creation Controversy," the editors observe:

Given the unsuccessful history of scientists' participation in the educational battles over evolution, it seems hopeful that a pluralistic position, promoting cultural tolerance and individual choice, has a better chance of ensuring that students at the very least learn what evolution is. (p. 7)

And what will such a pluralistic approach look like?

In actuality, the political side of the controversy reveals the type of fundamental epistemological and ontological questions that lie at the center of the postmodernist viewpoint. Arguments supporting the superiority of evolution on the basis of its being objective and providing rational knowledge fail to acknowledge that there are alternative valid ways of knowing the world. (p. 7)

An answer to the question of why these "alternative ways of knowing" should be taught in science courses is supplied by Michael J. Reiss in his concluding essay, "Teaching about Origins in Science: Where Now?"

The strongest argument, in my view, for teaching about religion in a science class, whether at school, college or university, is if it helps students better to understand science. (p. 200)

This theme is further developed in a number of ways by others in this collection. So, for example, Wolff-Michael Roth, in "Fundamentalist and Scientific Discourse: Beyond the War Metaphors and Rhetoric," focuses on dealing with the alternative discourses of fundamentalist religion and science when trying to teach evolution to reluctant learners. Roth suggests:

Teachers, individually and collectively, might want to think how they can provide opportunities not to convert students to one or the other discourse but of getting to know other ways of dealing with alternative discourses. (p. 121)

Michael Poole, in "The Scientific Enterprise and Teaching About Creation," states:

I shall argue that some rapprochement is possible between the parties at variance, while recognizing that a key issue, the age of the Earth, obviously cannot be resolved by both parties agreeing to move some way towards each other's position! I shall argue that teaching about Creation and a professional dedication to the scientific enterprise can, with integrity, go hand in hand. (p. 75)

Lee Meadows, in "Approaching the Conflict between Religion and Evolution," says

I envision a biology classroom where religious students are invited into the study of evolution without threat to their religious beliefs. Creating that kind of classroom requires that teachers help their religious student to manage, not resolve, the conflict... (p. 150)

What many of these writers seem to be embrace, either explicitly or implicitly, is the Gould-like approach of the "nonoverlapping magisteria". David L. Haury, in "Examining the Evolutionary Heritage of Humans," remarks:

Although individual scientists may claim that evolution rules out for them the need for a creator, science as a way of knowing is unable to make any definitive claims about the presence or absence of a supernatural entity. This is no way to test the idea empirically. (p. 135)

The message of these writers seems to be that if fundamentalist students and IDCs can be exposed enough to evolutionary theory (without insisting that they accept it), they will eventually come around to accepting evolution. This sounds suspiciously like Pascal's advice to the unbeliever who still has doubts about God's existence after being confronted with the Wager. What should one do if he or she is still not convinced to believe in God after being presented with the Wager? Pascal's advice, famously, is to fake it. Go through the motions: attend mass, take communion, say one's prayers, and eventually one will find that one does genuinely believe. The advice is dubious in the religious context. I believe it is equally dubious in the scientific context. All of these writers are working with the best intentions, but it is not clear that "managing" rather than "resolving" conflicts will be an effective strategy in 
science education, if the ultimate goal is to convey the truths of science.

Michael Ruse, in "The Warfare between Darwinism and Christianity: Who Is the Attacker and What Implications Does This Have for Education?" takes a somewhat different approach from these writers. Ruse, maybe most famous for Taking Darwin Seriously, and both a committed evolutionist and a committed unbeliever, takes to task some of the more uncompromising evolutionists for the difficulties that they create for any political resolution of the evolution/ creationism controversy. So, in discussing the work of Richard Dawkins, Ruse says:

...the Creationists know - to their great delight, as I have just said - that every time Dawkins opens his mouth, he is setting up prejudice against Darwinism in almost every conceivable stripe of Christian. (p. 38)

And:

Dawkins has been a wonderful champion of Darwinism. Unfortunately, when he emotes like this, he is doing nothing but harm - especially in the US todayto the cause of all kinds of evolution, and certainly making much more difficult the cause of those of us who are fighting to keep Creationism (including ID) out of the schools. All that the ID people have to do is show passages from Dawkins to their local school board or their congressman, and all hell breaks out. This is a fact. (p. 38)

Ruse himself admits to once being in the Dawkins' camp, so his concessions here are not so much a softening of his views on evolution, as a political strategy to defend evolution by, among other things, not giving ammunition to evolution's enemies. Whether the strategy is ultimately effective remains to be seen.

The most problematic article in this collection is Shaikh Abdul Mabud's "The Theory of Evolution: Teaching the Whole Truth." Although Mabud never explicitly rejects evolution in this essay, he comes as close as one can to do so without actually doing it. His stated concern is the way evolution is taught in Britain:

The intention of this chapter is to look at the way evolution is presented in some biology textbooks in British schools. It is not my primary purpose to present here an argument in support either of the theory of evolution or of its critics, as that would require much more comprehensive and rigorous analyses of various issues involved. Instead, I would like to show that the presentation of the existence of various forms of life in school textbooks and lessons is highly biased in favor of the theory of evolution and the scientific findings contrary to the evolutionary perspective are hardly mentioned. (p. 90)

From here, Mabud goes on not necessarily to present those alternative theories, but to attack evolutionary theory itself. In the course of his essay Mabud denies every claim made in the introductory paragraph of this review. He repeatedly denies that evolution is a fact, but only a way (and maybe not the most reasonable way) of explaining the variety of life on earth. So, for example:

Is evolution more likely than panspermia, or panspermia more likely than creation? Who knows? (p. 91)

And:

Evolution is not fact, but a way of explaining how the sequence happened, as are the theories of abrupt appearance and pan-spermia. All these truth claims have been subjected to scientific tests with different results, and students should be made aware of this. (p. 92)

Mabud's last phrase strikes me as a bit disingenuous. Teaching the history of science may require that students be made aware of previous, rejected theories, but there seems to be no more reason to teach panspermia in a course on evolutionary theory than there would be to teach phlogiston in a course on contemporary physics. Mabud, I think, does not regard creation and panspermia as dead scientific theories (as phlogiston is a dead physical theory), but theories that can rival the power of evolution. This seems to me to be driven by ideology rather than science.

Mabud goes on to add:

Nobody has witnessed evolution taking place. The process is far too too slow for us to conduct a valid, scientifically verifiable experiment to prove or refute its reliability as a scientific fact. (p. 92)

Here Mabud seems to be relying on the standard creationist claim that evolution is "only" a theory. Jones, in her essay, answers this in the following way:

It gives me great pleasure to agree with the creationist declaration that 'evolution is just a theory.' In that a theory is, by definition, a rational group of tested general principles of explanation for a class of phenomena, the theory of evolution is certainly a theory. The abundance of supporting evidence and the absence of major contradictions to evolution are the reason that it is considered to be such a well-established proposition. (p. 192)

Clearly Mabud does not accept this view of the nature of a theory. It seems as if, for Mabud, all theories are in some sense equally legitimate. This may be a bit too simplistic, but without this it is hard to understand his placing of 
evolution, panspermia, and creation on an equally plausible footing.

When Mabud does get around to mentioning what he considers the alternative sources that should be taught, he mentions two in particular: Michael Behe, and a book by Wendell R. Bird, The Origin of Species Revisited.

Michael Behe is a well-known figure in the Intelligent Design community. He is generally considered to be the major source of scientific legitimacy for Intelligent Design. And it is true that Behe is a tenured member of the Department of Biological Sciences at Lehigh University. But, if one visits Behe's web page on the Lehigh University web site, one finds the following disclaimer:

My ideas about irreducible complexity and intelligent design are entirely my own. They certainly are not in any sense endorsed by either Lehigh University in general or the Department of Biological Sciences in particular. In fact, most of my colleagues in the Department strongly disagree with them. (www.lehigh. edu/ inbios/faculty/behe.html accessed May 31, 2008.)

Behe's honesty and candor are laudable, and this certainly does not disprove his work, but it does make it clear that Behe's scientific expertise seems to lie outside of the area of evolutionary theory. To cite him as an authority in the field, as Mabud does, is somewhat misleading.

Maybe even more misleading is Mabud's citation of Wendell R. Bird. Mabud cites Bird's book as an objective presentation of evolution and its alternatives, containing "2,000 quotations and 5,400 notes" (p. 102). Mabud also characterizes the book as having

...no religious overtones, and it contains a balanced and meticulous presentation of the results of scientific investigation in the field of evolutionary biology and the theory of abrupt appearance....(p. 102)

This might very well lead one to see Bird as an objective observer reporting dispassionately on the controversies within his field. But the actual picture is somewhat different. Wendell R. Bird is not a scientist but is a lawyer by training. He also authored the "Resolution for Balanced Presentation of Evolution and Scientific Creationism" found on the website of the Institute for Creation Research (www.icr.org/ article/153/ accessed May 31, 2008). The final statements in the resolution of this document read as follows:

We are not trying to bring the Bible or Genesis into public schools. We are not trying to exclude evolution from public schools, unless creation is also excluded. We are asking public schools to be neutral between theories of the origin of the world, life, and man, and to give academic freedom of choice to students between these theories. We are asking public schools to present the scientific evidences for creation along with the scientific evidences for evolution.

The language here is revealing. The citation of the Bible and Genesis makes it clear that these are the accounts that will serve as the model for scientific creationism. At the same time that we are being assured that there is no attempt here to introduce religion into the classroom, religion is being used as the model for the theories that should be offered as alternatives to evolution. But why restrict it to these? If panspermia and creationism are as equally reasonable as evolution, then why not any number of other alternatives? After all, as David Hume argued so persuasively in his Dialogues Concerning Natural Religion, if we take the design analogy seriously, it is just as reasonable to conclude that there are many designers, even many generations of designers, as it is to conclude that there is only one designer. And yet how many Intelligent Design proponents would be content to have polytheistic creation accounts taught alongside their monotheistic accounts as plausible alternatives to evolution? None that I know of.

What appears to have happened here with Bird, and what Mabud has bought into by citing his book as an authority, is a confusion between legal reasoning and scientific reasoning. This is a tactic that is frequently taken in the Intelligent Design debate. We see it in Bird (a trained lawyer), and maybe even more notably in Philip Johnson, another major figure in the Intelligent Design debate, and also, not coincidentally, a professor of law. Whether such a move does more violence to the concept of legal reasoning or to the concept of scientific reasoning may be an open question, but it certainly doesn't do either any good.

In the end, the prospects for resolving the creation/ evolution conflict do not appear to be very hopeful. As pointed out throughout this review, numbers of scientists and science educators are finding ways to make concessions to the religious mindset in their classrooms. But this seems to be a one-sided effort. How many fundamentalist preachers are making similar efforts in making concessions to the theory of evolution? I suspect the number isn't much greater than 0 . In the controversy, all the efforts at resolution seem to be one-sided. This does not lend itself to optimism concerning any foreseeable end to these discussions. It is as if one side in a game insists on following the rules while the other side is free to dispense with the rules whenever it is convenient to do so. The post-modern strategy of replacing talk of truths with talk of alternate discourses, or alternative world views, does nothing to end the game. It simply puts more players on the field - many who do not belong there.

The essays in this collection do a good job of presenting these issues and offering some solutions. But until we start to see similar collections from the fundamentalist camp, the future of the controversy does not seem bright. 